\title{
The Elder Health Information Technology Framework for Geriatric Care in Rural India: A Policy Initiative
}

\author{
Keya Sen ${ }^{*}$, Stan Ingman ${ }^{2}$ \\ ${ }^{1}$ Department of Health Science, College of Allied Health and Nursing, Minnesota State University Mankato, Mankato, USA \\ ${ }^{2}$ Department of Rehabilitation and Health Services, College of Health and Public Service, University of North Texas, Denton, USA \\ Email: ^keya.sen@mnsu.edu, Stan.Ingman@unt.edu
}

How to cite this paper: Sen, K. and Ingman, S. (2021) The Elder Health Information Technology Framework for Geriatric Care in Rural India: A Policy Initiative. Communications and Network, 13, 12-24. https://doi.org/10.4236/cn.2021.131002

Received: December 27, 2020

Accepted: February 22, 2021

Published: February 25, 2021

Copyright $\odot 2021$ by author(s) and Scientific Research Publishing Inc. This work is licensed under the Creative Commons Attribution International License (CC BY 4.0).

http://creativecommons.org/licenses/by/4.0/ (c) (i) Open Access

\begin{abstract}
Healthcare monitoring and analysis of healthcare parameters is a reality to reduce costs and increase access to specialist and experts that holds the future for geriatric care in India. This paper proposes distinct methods towards the implementation of rural elder health information technologies (IT), which includes electronic medical records, clinical decision support, mobile medical applications, and software driven medical devices used in the diagnosis or treatment of disease for the older adult population in the villages of India. The purpose is online patient satisfaction at the microlevel (village panchayat) through methods accessible and affordable by establishing a common standard of operations at the village primary care units giving way to early disease detection and routine screening among the aged population avoiding institutionalization. The rural elder health IT framework is of great interest for all stakeholders in the field, as it benefits the investors and the consumers, adding to the technological infrastructure, thereby opening new avenues of research in health informatics, telemedicine and enhancing the scope of geriatric research, which in turn enhances the health-related quality of life for the rural older adults in the remote villages of the nation.
\end{abstract}

\section{Keywords}

Older Adults, Elder Health Information Technology, Quality of Life, mHealth, Social Network Interface, Service Quality

\section{Introduction}

Equitable access to safe and inclusive health information technology for the old- 
er adults is an essential requirement in the socio-economic milieu of India across various occupational, cultural, and economic groups, not overruling gender and physical capabilities. The proportion of older adults in the demography of India is steadily increasing, causing health care costs to rise dramatically. The need for elder health information technology (IT) infrastructural set up in rural India is a pressing need and an important aspect of eldercare especially in the remote corners of the nation, inhabited by the underserved, rural and agrarian population. The elder health IT implementation framework is a future move to enhance the awareness in elderly towards utilization of technology-based devices that promotes health, well-being, and the quality of life [1]. The qualitative and quantitative availability of primary health care facilities in the villages does not satisfy the defined standards of the World Health Organization in most parts of rural India [2]. These centers are mostly disconnected from the online health support that is available in the urban areas. The existing healthcare infrastructure lacks on its strength for sub-centers, primary health centers and community health centers for seniors and procures a heavy daily loss of wages [3]. This calls for reforms and capacity development for elder health IT growth in such areas.

The elder health IT Implication is a potential solution to healthcare in the villages. Governmental collaboration at the local level with the private sector can bring benefits for the rural gentry through subsidies and provide for developmental network through the existing health IT infrastructure [4]. If the private insurance companies reach out to the rural masses for universal coverage at a lower cost through the health IT network, the public sector can also leverage the private sector's capital for the development of public health IT through the projects on healthcare management and universal coverage for long term care model in the villages outside of public funding sources. If the proposed elder health IT infrastructure fosters health service delivery efficiency and is effective in the remote areas, the government can focus on its core business such as coordination and monitoring the service quality in terms of healthcare accessibility for rural seniors [5]. The private sector has better technology than the public sector, for example, the Reliance group "JIO" network or the Aditya Birla group "IDEA" network is economically viable and provides adequate subsidies that could be used to build the infrastructure and network. The possibility of cost-sharing and risk transfer in public projects, with a return on investment would provide for sustainable health care, which would give the older adults in the villages, easy access to the invaluable expertise of the private sector in the areas of user satisfaction, productivity gains and efficiency.

\section{Background}

In India, the geriatric age group, 60 years and above constitute $8.6 \%$ of the total population [6]. The projected increase in the size of geriatric population is 118.1 million by 2021 and 173.18 million by 2026 as shown in Figure 1. About 3.5\% of the elderly are above 80 years of age, with women in the majority [7]. This group 


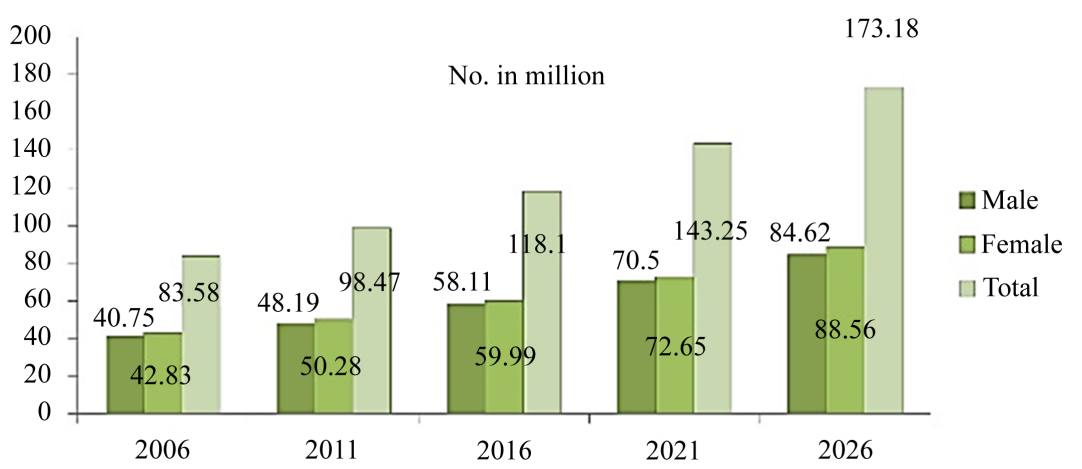

Figure 1. Projections of the aging population of India, now and the future. Source: Population India. Chapter-2. Census of India 2010.SRS report.

is socially vulnerable and in need of assistive technologies to keep them engaged and connected to health care services. The use of mHealth to resolve health issues can bring about a change towards affordable and accessible health care for the minority (2.4\%) of the elderly living alone that constitutes $3.49 \%$ of women and $1.42 \%$ of men [8].

In rural India, healthcare resources and accessibility to healthcare services for seniors are a major problem, hence mHealth is a viable solution with a simple smartphone, a low-cost internet-enabled device, that can be used by old people for maintaining a healthy lifestyle. The use of applications like fitness trackers, medication reminders, doctor appointments, diagnostics, preventive care, and medical service search remain unfulfilled without elder health IT initiatives at the micro level [9]. For example, the maternal and child health indicators in the state of Madhya Pradesh specify the need for implementation of "eSanjeevani tele-medicine" platform to effectively manage the health of the highly dispersed population [10].

The major challenges facing rural India are bottlenecks in emergency response services to deliver care and medication at the right time through automatic or manual alert to authorities from internet driven devices. Only some areas like Kolar region in Karnataka have technology driven telemedicine project where the software allows for assessments, monitoring and training without compromising the quality of care. Located about $60 \mathrm{~km}$ from the main center in Bangalore, this Dementia Care Unit offer financially viable service with a team of senior medical staff in Bangalore remotely monitoring patients and providing advice to the 35-bed facility thereby significantly reducing the cost of care [10].

India has a favorable climate, system maturity and wide network for education and training for information and communication technology, but the system suffers from the deficiencies like insufficient investment by the concerned stakeholders, shortage of gatekeepers and volunteers, little collaboration between the government and user-industries, less consideration to quality and evaluation for quality implementation. There is lack of initiative on the part of the Indian corporate industry and the institutional climate is often dominated by the dependency motive [11]. With the inculcation of information and communication 
technology, various applications can be further designed for the growth of elder health IT infrastructure in rural areas by central, state as well as local government to foster equitable healthcare.

Understanding healthcare needs through continuous monitoring of data for the spread of common diseases is not possible as the elder health IT infrastructure is inadequate to integrate the rural hospital, as the center for acute and inpatient care, into the broader health care system, and facilitate quality care through patient experience, care safety, equity, and sustainability. Older patients in the villages are not able to move with their privacy and dignity from initial referral through local hospitals to specialist tertiary centers and discharge to appropriate care at home or community hospital. An integrated elder health IT in rural areas can support the delivery of information to ensure patients, care givers and health professionals to access information they need. This reduces health disparities both in outreach provision of care thereby reducing travel costs and need for doctor office visits [12] which are otherwise difficult in the remote corners of the nation. The situation calls for inclusive care to be initiated in terms of financing, supporting, and empowering the family members/caregivers to practice and be aware of geriatric e-health services [13]. The elder health IT framework opens avenues for rural electronic medical records, clinical decision support, mobile medical applications, and the software driven medical devices for the diagnosis or treatment of disease following online methods [14].

\section{The Problem Statement}

Access to basic care via the elder health IT network is a fundamental requirement for improving the health-related quality of life and sustainable aging [15] in Indian villages. Hospital efficiencies are lacking with the supply of multiple terminals around the hospital that allows real-time access to an interactive database of inpatient admission and discharge information, with referral details, patient information, and location. There is almost no capacity and activity management system that could be linked to the wider health and social care providers and personal communication devices detailing contact details to each member of the clinical team in each shift. Provision of applications with "National Initiative on Care of Elderly" (NICE) regulation guidelines, national and local protocols does reduce errors, but the available care accessibility is not commensurate to the conditions suffered or the existing disparities and even where the care is physically accessible, costs of accessing this care hinder affordability. Hence the older adults in the villages are challenged with declining health in the absence of technology and care infrastructure and suffer wage loss seeking care.

\subsection{Objectives}

This paper proposes the methods and policy initiatives towards implementation of rural elder health IT framework for the development and evaluation of a new consumer directed care approach to community aged care service delivery 
structure in the village panchayat regions of India. The study also determines the cost-effectiveness of this approach to community aged care that also brings profits for the IT investors in the market.

\subsection{Research Question}

Can the implementation of the elder health IT infrastructure in rural India provide for accessible and affordable geriatric care in its villages?

\subsection{Hypotheses}

H1: The rural elder health IT framework is a potential area for leverage to gain accessible and affordable geriatric care in the villages.

H 2: Sufficient investment by the concerned stakeholders, involvement of competent core community volunteers, and collaboration between government and user-industries, can frequently up-grade the e-health network in the villages.

\subsection{Theoretical Framework}

The Social Exchange Theory provides the foundation for this proposed policy initiative. George Homans in his theory suggests that "social exchange" is the key point of reference in all human behaviors, and human behavior is always involved in the process of resource exchange out of the desire to receive something. Hence implementation of the elder health IT in the villages enhances mHealth services that positively impacts the sharing of awareness and knowledge at the micro level, promote a sense of self-worth among the users and perceived social support. Again, when health related data and information is available, both the health care providers and consumers benefit, and future research possibilities are heightened [15]. The optimum use of existing community resources, in an age friendly environment, also engages rural seniors socially in activities like computer training workshops that fosters community capacity as well [12].

The individual perceptions, attitude, behavior, and acceptance of the elder health IT framework for healthcare access are grounded on the Technology Acceptance Model (TAM). The TAM provides strong evidence that the perceived usefulness of the IT will impact on the clinician and patient acceptance and subsequent use of health IT as shown in Figure 2. Rural elder health IT framework may find the possible prevention measures to eradicate and reduce the spread of diseases, new technology in diagnosis that reduce the time and cost involved in care. The structure of the elder health IT is suggestive of the fact that it can bring sustainable outcomes and is not difficult to use by the providers, payers, policy makers and the consumers in health care service delivery [16].

\subsection{Proposed Model of Elder Health IT Framework}

The elder health IT framework is designed on the model of patient centered care as shown in Figure 3. The goal is patient satisfaction at the microlevel (village/panchayat) through e-services for accessible and affordable care. At the 


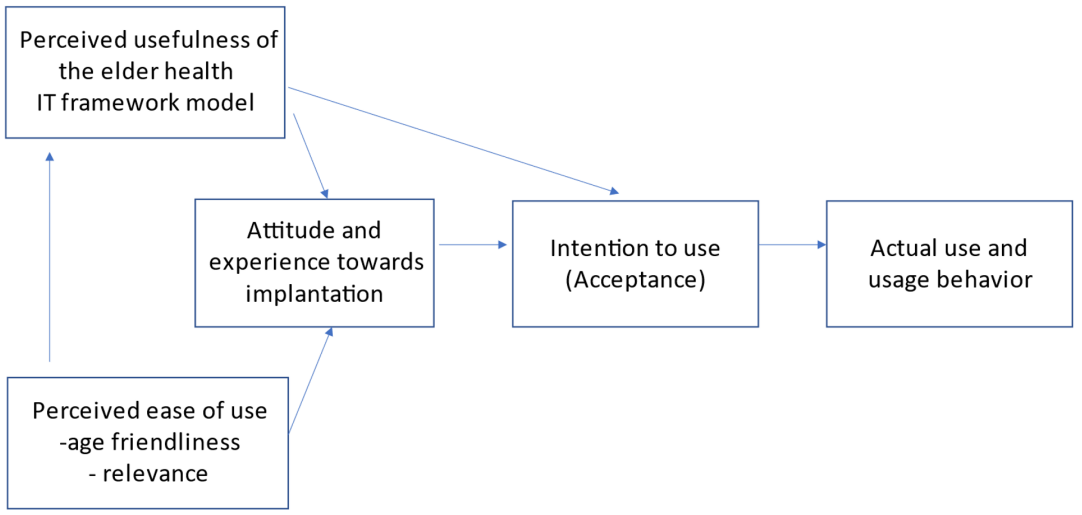

Figure 2. The acceptance of technology and mHealth services by older adults, adapted from Naeini, 2012 [17].

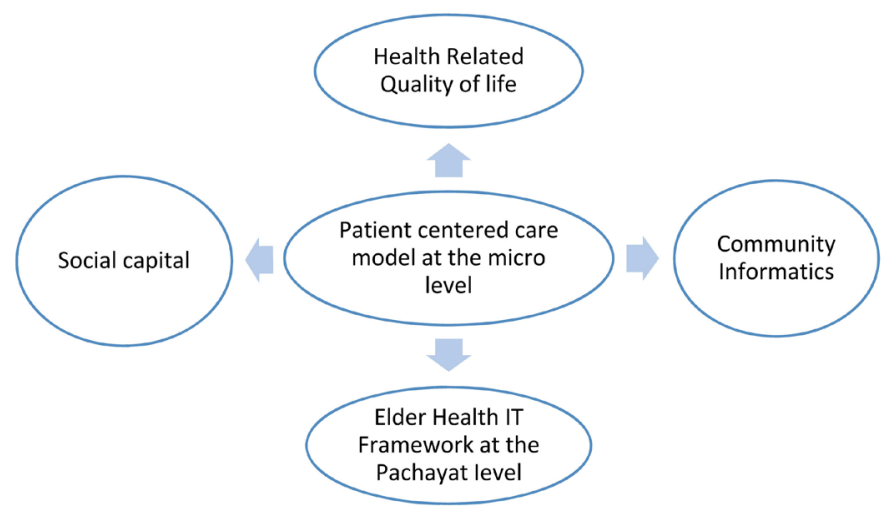

Figure 3. The patient centered care model.

meso (societal, governmental-state, and federal) level, the communities are involved through outreach programs for growth of the elder health IT framework and activation of the system in the village health centers [18]. The primary care units at the village level establish the common standard of operations and the providers and staff ensure the accessibility to electronic health record and other information for the clients. At the macro level, the policy makers decide on the modification of laws to check on data breach and privacy control through legislations [19].

The stakeholders of the program include the older adults above 65 years, the providers, both formal and informal care givers, the payors, both the private and government run insurance agencies, and the policymakers at the local level. Following the idea of the "Landmark Projects Focused on Rural Reform" [20] in India, a system of e-health was developed for the village of "Mourigram" in West Bengal. With the evolution of national e-governance plans, various e-health applications could automatize the various segments of the healthcare services across the villages. The already existing system of e-governance was elaborated to health care service delivery system [21] for the project. The Howrah district main health care unit was connected to the "Mourigram" primary care center through the system of LAN and WAN network as shown in Figure 4. Cost 


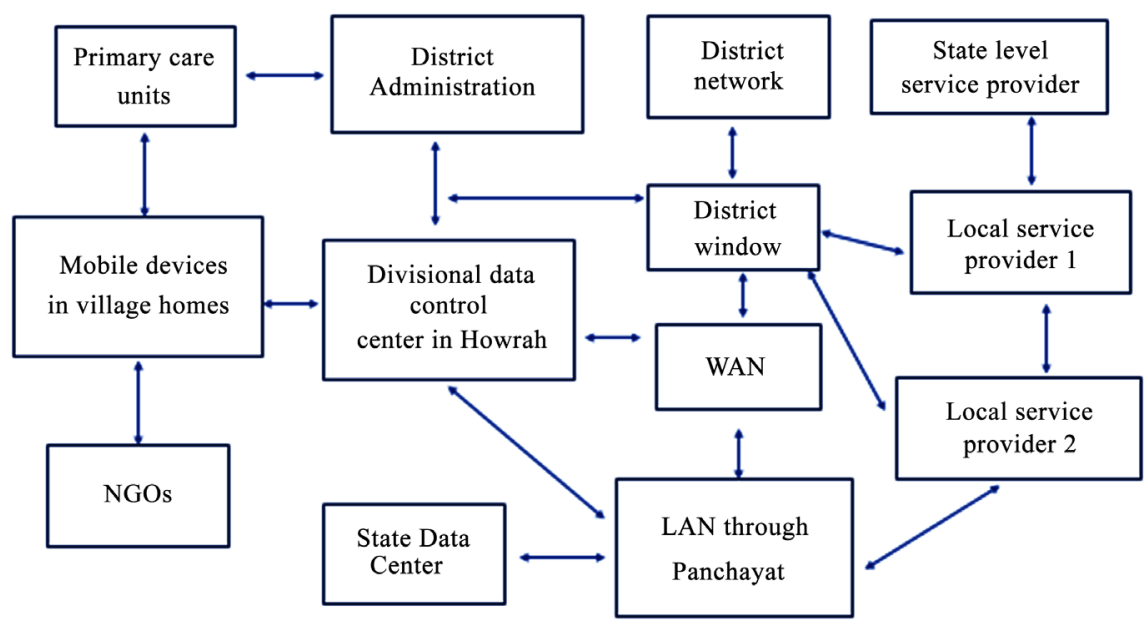

Figure 4. The mHealth service network for the older adults in the villages.

control and cost reform were emphasized at every step of implementation of the elder health IT through the usage of already existing information communication technology model in the state. A reality check was done by the stakeholders [19] following legislative enactment for regulating village e-health administration and service delivery.

This model of patient centered care as is shown in Figure 4 is based on the idea of patient empowerment and participatory medicine fostered by the volunteer groups and the non-governmental organizations (NGO) through patient education to the use of technology and general health education programs and active participation towards the acceptability of the elder health IT framework.

\section{Methodology}

Four distinct phases of implementation and adaptation of a regulation for the establishment of the health IT for elderly health care in the villages were proposed. The framework was initiated in "Mourigram" of the Howrah district of West Bengal. A qualitative research analysis was done with the use of focus group interviews in the region.

\subsection{Phase 1. Calculating the Incremental Changes}

At the government level, we calculated the incremental changes in health, quality of life and well-being outcomes for older people. A needs assessment was conducted to determine the cost-effectiveness of the approach. Focus group interviews helped us to make an ecological assessment of the issues relating to lives of older people in relation to their social participation, family relationships, confidence and self-esteem. Interviews in "Mourigram" revealed the fact that the older women in the region were completely unaware of technology use or e-services in Healthcare. The results of the qualitative analysis were employed to inform the most appropriate attributes and levels for the implementation of the elder health IT, thereby reflecting recommendation of best practice guidelines 
for its the development in the rural areas.

\subsection{Phase 2: Introduction and Development of the Elder Health IT Model}

A new service delivery approach was developed with the help of stakeholders in the region. The village postman, the meter reading guy, and the panchayat workers helped us to identify the specific regions in need of service use in "Mourigram". The elder health IT infrastructure was set up in collaboration with the micro level partner organizations [22] like the "Drishti" for eye care. The findings from the interviews in phase 1 was applied to identify and operationalize the features of the elder health IT service delivery approach in the region. The new approach included access to a care coordinator provided by each of the macro level partner organizations like the Aditya Birla Group, who were responsible for providing opportunities for consumers and their informal care givers to direct and manage their own care using the elder health IT model as shown in Figure 4. Gadgets like smart phones and tablets (supported by IDEA network) that facilitate mHealth services were distributed among 20 community members after initial training by "Suchetona" (NGO) on device usage. The use of the elder health IT in this rural set up (community centers, and primary health care offices) enabled $96 \%$ of those who had no official social security such as Provident fund, gratuity, or pension after retirement [23] to be included in the system of care.

The community level as it appears in Figure 5 was found to be the appropriate intermediate level for negotiation between the national level and the individual level for any form of policy to work out [24]. The connectivity research and inclusion research in "Mourigram" were brought together in a community-based approach, which facilitated social network interface at the macro level to reach out to the micro level to address various health needs.

\subsection{Phase 3: Economic Evaluation}

This Phase involved the implementation and economic evaluation of the new approach developed in phase 2. The funds for the entire framework were provided by the Indian multinational telecommunications' private company-Aditya Birla Group who had 70\% of the share of the elder health IT framework, operative in the targeted area. After the budget for "Mourigram" panchayat area requirement was sanctioned by the state government, a thorough process

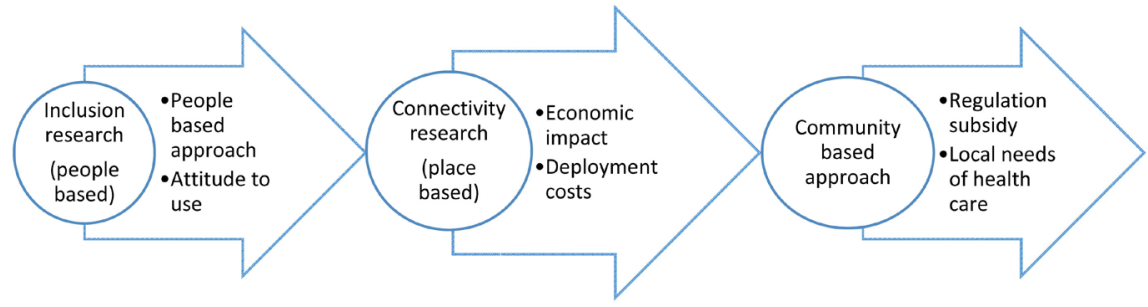

Figure 5. Negotiation through the community level. 
evaluation was done for cost control and reforms particularly at the local primary care units to connect them directly to the Howrah district-controlled health care centers. The objectives at this phase were to calculate the incremental changes in the structural framework and its progressive use in health care delivery and well-being outcomes for older people and their informal care givers.

\subsection{Phase 4: Investigation of Post Intervention Attitudes and Preferences}

In this phase we measured the extent to which the attitudes and behavioral preferences of older people, informal care givers and operational staff had changed owing to the use of the elder health IT. This was completed by a comparison of the baseline and 6 months post intervention of the elder health IT implementation. When interviewed, about $95 \%$ of older women in the region expressed their desire for more services in addition to the services available through the initiated framework. A positive correlation existed between the use of the elder health IT and the cost-effective benefits of health care, which suggested that further initiatives could be undertaken where the community volunteers and medical, paramedical, and indigenous providers could be trained to identify elderly patients in service need, and comprehensive surveys of morbidity and functional status could be conducted. The "Mourigram" primary care units, community partners and local party leaders were engaged in capacity building of health IT services for the region's geriatric community and healthcare.

\section{Discussion}

The NGOs along with the federal government have widely contributed to implementing the national agenda for geriatric care by conducting studies and offering multifaceted services to seniors. "Help-Age India" [25] offers different kinds of programs such as old age home models, day care centers, health clinics and educational workshops for the elderly which were idealized to be used in "Mourigram". Sharing of the data from the 4 phased the elder health IT implementation framework provided adequate information on future research for the elder health IT implementation and programs via its Research and Development journal. The All-India Senior Citizens Confederation (www.aisccon.org) also recognizes the elder health IT through the ICT framework through its newsletter titled "The Twilight Years". The advocacy for the implementation of the elder health IT framework was done by the "Suchetona", a leading web-based discussion group for seniors in the Howrah Region. We also planned to use the Dignity Foundation; the Harmony Foundation; and the "Silver Inning Foundation" for advocacy programs for the implantation of the elder health IT framework in other parts of the country [26].

Challenges within national healthcare policies and government spending are at the forefront when considering the lack of prioritization of primary care service. India's poor government aid for healthcare services results in less importance to primary health care needs inviting the chronic ailments and disabilities 
for the rural poor gentry. The elder health IT based multi-disciplinary specialist care in "Mourigram" integrated the care service for orthopedics, ophthalmology, and cardiovascular health, which contributed to reduce the high rates of morbidity by $3 \%$ in the first three months.

Along with the existing policies on geriatric care like the "Indian National Policy on Older Persons" (NPOP) and "Maintenance and Welfare of Parents and Senior Citizens Act" (MWPSCA), that primarily addresses the housing and care requirements of the elderly, the elder health IT supported by private companies will promote the goal of creating enabling environments for healthy lifestyles, early detection, and routine screening among the aged avoiding institutionalization. A healthy future is possible with the "The National Policy on Information Technology" approved by Government of India on 2012 that visualizes the utilization of IT in the village as an engine for rapid, inclusive, and sustainable development of the Indian economy.

The introduction of "e-Choupal", a system for rural commercial transactions established by "The Indian Tobacco Company", a conglomerate in India is working well to link directly with rural farmers via the internet for procuring agricultural and aquaculture products like soybeans, wheat, coffee, and prawns. The proposed elder health IT for healthcare in the villages can establish connectivity and information networks in a similar style. The National Institutes on Aging funded by the central government, in Delhi and Chennai are already undergoing research on the implementation of the elder health IT to support geriatric care [21].

The Ministry of Social Justice and Empowerment, charged with implementing the policy of NPOP and MWPSCA, has had no budget for this new responsibility. Instead, it was expected to coordinate implementation through budgets of other ministries. Involving the elder health IT stakeholders (especially the for-profit organizations of the Birla group) and community partners like "Drishti" will help reach major goals to improve primary health care and accentuate research and training in geriatrics. It would in turn strengthen the family as the primary eldercare provider and value seniors as human resource partners in national economic development [27].

\section{Conclusion}

The Elder health IT framework is an integrated and responsive system with the involvement and collaboration of family, community, and the government to meet the needs and challenges of elderly health in rural India. The integration of the social service institutions in "Mourigram" with the provisions of geriatric care through an online framework was a cost-effective way to access healthcare. The framework was a steppingstone to address the social challenges, reduce health inequities and enhance the quality of life for the elderly [28]. The elder health IT would further connect the elderly to recreational centers, elderly nutrition programs, exercise facilities and senior citizen clubs as well. This framework can bolster social engagement, autonomy, and privacy of the seniors in India. 
Effective strategies using the online framework for enhancing gerontological, social and clinical education programs [29] would promote geriatric health care and utilize the sizable human resources of the older adults in India adding respect and value to their lives.

\section{Conflicts of Interest}

The authors declare no conflicts of interest regarding the publication of this paper.

\section{References}

[1] Sudha, S., Suchindran, C., Mutran, E.J., Rajan, S.I. and Sarma, P.S. (2006) Marital Status, Family Ties, and Self-Rated Health among Elders in South India. Journal of Cross-Cultural Gerontology, 21, 103-120.

https://doi.org/10.1007/s10823-006-9027-x

[2] Kurian, G.A. (2018) Elderly Care-A Case for the CSR Initiatives. Business Ethics and Leadership, 2, 84-93. https://doi.org/10.21272/bel.2(3).84-93.2018

[3] Singh, S. and Badaya, S. (2014) Health Care in Rural India: A Lack between Need and Feed. South Asian Journal of Cancer, 3, 143-144.

https://doi.org/10.4103/2278-330X.130483

[4] Das Aundhe, M. and Narasimhan, R. (2016) Public Private Partnership (PPP) Outcomes in e-Government-A Social Capital Explanation. International Journal of Public Sector Management, 29, 638-658. https://doi.org/10.1108/IJPSM-09-2015-0160

[5] Yan, Z., Wang, T., Chen, Y. and Zhang, H. (2016) Knowledge Sharing in Online Health Communities: A Social Exchange Theory Perspective. Information \& Management, 53, 643-653. https://doi.org/10.1016/j.im.2016.02.001

[6] Usha, P., Kishore, S., Singh, M., Jain, B., Kumar, D., Kumar Reddy, N.K., Rehan, A. and Ranjan, S.K. (2020) A Study of Morbidity Profile among Geriatric Population in Uttarakhand: A Community Based Cross-Sectional Study. Journal of Family Medicine and Primary Care, 9, 3677-3681.

https://doi.org/10.4103/jfmpc.jfmpc_256_20

[7] kaviarasu, S.J. and Dinesh, J. (2019) Facets of Challenges Experienced By Geriatric Population in India: A Critical Study.

[8] Rajan, S.I. and Kumar, S. (2003) Living Arrangements among Indian Elderly: New Evidence from National Family Health Survey. Economic and Political Weekly, 38, 75-80.

[9] Madanian, S., Parry, D., Airehrour, D. and Cherrington, M. (2019) mHealth and Big-Data Integration: Promises for Healthcare System in India. BMJ Health and Care Informatics, 26, e100071. https://doi.org/10.1136/bmjhci-2019-100071

[10] Singh, C., Basu, R., Srinivas, A., Halanaik, B., Andaleeb, R., Madhushree, M. and Bazaz, A. (2016) Livelihood vulnerability and adaptation in Kolar District, Karnataka, India: Mapping Risks and Responses Short Report.

[11] Jain, R. and Agrawal, R. (2007) ICT Education and Training Services: Current Scenario and Prospects in India. Vision, 11, 41-55. https://doi.org/10.1177/097226290701100206

[12] Sen, K. and Prybutok, G. (2019) A Quality Mobility Program Reduces Elderly Social Isolation. Activities, Adaptation \& Aging, 45, 1-13. 
https://doi.org/10.1080/01924788.2019.1700881

[13] Luxon L. (2015) Infrastructure-The Key to Healthcare Improvement. Future Hospital Journal, 2, 4-7. https://doi.org/10.7861/futurehosp.15.002

[14] Ronquillo, J.G. and Zuckerman, D.M. (2017) Software-Related Recalls of Health Information Technology and Other Medical Devices: Implications for FDA Regulation of Digital Health. The Milbank Quarterly, 95, 535-553. https://doi.org/10.1111/1468-0009.12278

[15] James, K.S. (2011) India's Demographic Change: Opportunities and Challenges. Science, 333, 576-580. https://doi.org/10.1126/science.1207969

[16] Campbell, J.I., Aturinda, I., Mwesigwa, E., Burns, B., Haberer, J.E., Bangsberg, D.R., Siedner, M.J., et al. (2017) The Technology Acceptance Model for Resource-Limited Settings (TAM-RLS): A Novel Framework for Mobile Health Interventions Targeted to Low-Literacy End-Users in Resource-Limited Settings. AIDS and Behavior, 21, 3129-3140. https://doi.org/10.1007/s10461-017-1765-y

[17] Naeini, F.H. (2012) Usage Pattern, Perceived Usefulness and Ease of Use of Computer Games among Malaysian Elementary School Students. Research Journal of Applied Sciences, Engineering and Technology, 4, 5285-5297.

[18] Ratcliffe, J., Lancsar, E., Luszcz, M., Crotty, M., Gray, L., Paterson, J. and Cameron, I.D. (2014) A Health Economic Model for the Development and Evaluation of Innovations in Aged Care: An Application to Consumer-Directed Care-Study Protocol. BMJ Open, 4, e005788. https://doi.org/10.1136/bmjopen-2014-005788

[19] Noor, M.M. (2018) Rural Community Digital Technology Connectedness: Does ICT in Rural Area Contributes to Rural Development in Malaysia? The Social Sciences, 13, 316-322.

[20] Kumar, P., Kumar, D. and Kumar, N. (2014) ICT in Local Self Governance: A Study of Rural India.

[21] Acharya, B. (2018) Modeling Local Government's Perception towards Implementation of ICT Infrastructure and Services through Public Private Partnership Mechanism: Case of Nepal.

[22] Panruti, R.V., Liebig, P.S. and Duvvuru, J. (2015) Gerontology in India. The Gerontologist, 55, 894-900. https://doi.org/10.1093/geront/gnv022

[23] Selvaraj, S., Karan, A. and Madheswaran, S. (2014) Elderly Workforce Participation, Wage Differentials and Contribution to Household Income. In: Population Ageing in India, Cambridge University Press, Cambridge, 42-73. https://doi.org/10.1017/CBO9781139683456.004

[24] Salemink, K., Strijker, D. and Bosworth, G. (2017) Rural Development in the Digital Age: A Systematic Literature Review on Unequal ICT Availability, Adoption, and Use in Rural Areas. Journal of Rural Studies, 54, 360-371.

https://doi.org/10.1016/j.jrurstud.2015.09.001

[25] Welfare and Development Programs. https://www.helpageindia.org/our-work/welfare-development

[26] Prasad, S. (2012) Deprivation and Vulnerability among Elderly in India.

[27] Patel, V., Chatterji, S., Chisholm, D., Ebrahim, S., Gopalakrishna, G., Mathers, C., Reddy, K.S., et al. (2011) Chronic Diseases and Injuries in India. The Lancet, 377, 413-428. https://doi.org/10.1016/S0140-6736(10)61188-9

[28] Lena, A., Ashok, K., Padma, M., Kamath, V. and Kamath, A. (2009) Health and Social Problems of the Elderly: A Cross-Sectional Study in Udupi Taluk, Karnataka. Indian Journal of Community Medicine: Official Publication of Indian Association 
of Preventive \& Social Medicine, 34, 131. https://doi.org/10.4103/0970-0218.51236

[29] Dey, S., Nambiar, D., Lakshmi, J.K., Sheikh, K. and Reddy, K.S. (2012) Health of the Elderly in India: Challenges of Access and Affordability. 